\title{
Compensation Effects in the Non-isothermal Pyrolysis of Wood
}

\author{
SIEW MEI LIM and MICHAEL YIT LIN CHEW \\ Department of Building \\ School of Design and Environment \\ National University of Singapore \\ 4, Architecture Drive, Singapore 117566
}

\begin{abstract}
A considerable variation exists in the kinetics constants that were derived using Arrhenius equation in the study of the reaction kinetics for wood pyrolysis. It is of interest to evaluate whether compensation behaviours that usually associate with a series of related reactions might have contributed to the observed variations in the nonisothermal pyrolysis kinetics. The study of the compensation effects was intended to seek a logical explanation for the observed variations of the apparently large and differed values of activation energy and pre-exponential factors. Statistical regression analyses were performed to correlate the Arrhenius parameters derived from the non-isothermal Thermogravimetry Analysis (TGA) data. To gain an insight on the competing reactions so as to expound the varied kinetic data, these transition kinetics were also analyzed for exothermic transition using Differential Scanning Calorimetry (DSC) for heat of pyrolysis. This study showed that compensation effect existed, but found that the enthalpy of transition held a stronger proposition on the transition kinetics.
\end{abstract}

KEYWORDS: fire chemistry, wood pyrolysis, compensation effects, activation energy, pre-exponential factors, heat of pyrolysis

\section{NOMENCLATURE LISTING}

\begin{tabular}{llll}
$A$ & pre-exponential factor $\left(\mathrm{min}^{-1}\right)$ & \multicolumn{2}{l}{ Greek } \\
$E$ & activation energy $(\mathrm{kJ} / \mathrm{mol})$ & $\sigma \quad$ standard deviation \\
$k$ & rate constant & \multicolumn{2}{c}{ subscripts } \\
$k_{\text {iso }}$ & isokinetic rate constant & $E$ & activation energy $(\mathrm{kJ} / \mathrm{mol})$ \\
$R$ & molar gas constant $(8.314 \mathrm{~J} / \mathrm{K} . \mathrm{mol})$ & $i$ & running number \\
$T$ & absolute temperature, $\mathrm{K}$ & & \\
$T_{\text {iso }}$ & isokinetic temperature $(\mathrm{K})$ & \\
$\Delta H$ & heat of pyrolysis $(\mathrm{J} / \mathrm{g})$ &
\end{tabular}

\section{INTRODUCTION}

The Arrhenius equation has been popularly used in the pyrolysis of cellulosic materials to present the rate data as a function of temperature [1]. The Arrhenius equation is expressed as:

$k=A \exp (-E / R T)$ 
where $k$ is the rate constant, $A$ is the pre-exponential factor and $E$ is the activation energy. The logarithmisation of pre-exponential factors $(A)$, when plotted with the activation energies $(E)$ could exhibit a linear relationship for a series of related reactions. This relation is referred to as the "compensation effect" or "isokinetic effect," or the $\theta$ rule. Compensation effect is of interest to pyrolysis reaction since it expounds the relation given a group of rate processes. The linear relation may be obtained from linearised Arrhenius Equation that was expressed as follow:

$\ln A=\ln k_{\text {iso }}+E / R T_{\text {iso }}$

where $k_{\text {iso }}$ is the isokinetic rate constant and $T_{\text {iso }}$ is the isokinetic temperature.

Pyrolysis kinetics of hardwood samples showed a considerable variation in the kinetics constants derived from using the non-isothermal thermogravimetry analysis (TGA) [2]. The variation in the kinetic constants within the same thermochemical regime for hardwood samples was large and random, showing different values of activation energies. The rampant activation energies made a compelling reason to investigate the existence of interrelated kinetic behaviour within a group of rate processes using the compensation effect.

It would be superfluous however to discuss the reactivity among the groups of kinetic parameters for a set of related reactions without considering the enthalpy of transition. The quantification of the energetics of the pyrolysis phase provides an identification of the pyrolysis pathway of cellulose, where the dehydration process was characterized by exothermic reaction; the depolymerisation, by an endothermic process [3]. Further, the quantum of the energetic related to the chemical reaction has been shown to relate to the extent of the pyrolysis reactions where the occurrence of the secondary pyrolysis would result in a higher quantum of heat evolved as compared to the occurrence of the primary pyrolysis alone [4]. Indeed, the measurement of the enthalpy changes imparts a fingerprinting of the pyrolysing components and their behaviour and enables the pyrolysis of the biomass to be related to the known features of the pyrolysing components, therefore providing a quantitative framework for analyzing and understanding the complex pyrolysis behaviour of wood.

In this study, statistical procedures were performed to treat the data described in Eq. 2 to detect the linear compensation behaviour. Differential Scanning Calorimetry (DSC) measured the exothermic and endothermic transitions that produced the peak areas which were proportional to the total enthalpy change in the thermograms.

\section{EXPERIMENTAL}

\section{Non-isothermal Thermogravimetric Analysis (TGA)}

The samples of Balau, Kapur, Meranti and Durian were cut from the knot-free boards of the respective hardwood, milled and passed through a 40-mesh screen. The hardwood samples were heated in the alumina crucibles with a constant heating rate of $12^{\circ} \mathrm{C} / \mathrm{min}$ [5], with dynamic heating commencing from $25^{\circ} \mathrm{C}$ until $600^{\circ} \mathrm{C}$. The system was first purged for air using nitrogen, and then maintained inert with the flowing nitrogen of $90 \mathrm{ml}$ per min. 


\section{Differential Scanning Calorimetry (DSC)}

The same experimental conditions such as heating rate and atmosphere were as that of the TG experiments were imposed, except that the weighted samples for DSC analysis were to be placed in the aluminum pan and hermetically sealed. Thermal analysis was carried out at a constant heating rate of $12^{\circ} \mathrm{C} / \mathrm{min}$ in an inert atmosphere from $25^{\circ} \mathrm{C}$ to $550^{\circ} \mathrm{C}$. The selection of the transition peak and baseline were performed using the Universal Analysis software, version 2.5H 1998-1999 @ TA Instruments Inc.

\section{METHODOLOGY}

Based on the linearised Arrhenius equation stated in Eq. 2, the statistical procedures proposed by Agrawal [6] were adopted as follows:

$$
\begin{aligned}
& \text { Slope }=\frac{1}{R T_{\text {iso }}}=\frac{n \sum E_{i} \ln A_{i}-\sum E_{i} \sum \ln A_{i}}{n \sum E_{i}^{2}-\left(\sum E_{i}^{2}\right)} \\
& \text { Intercept }=\ln k_{\text {iso }}=\frac{\sum \ln A_{i}-\left(\frac{1}{R T_{\text {iso }}}\right) \sum E_{i}}{n} \\
& \text { Correlation coefficient }=\frac{\left(1 / R T_{\text {iso }}\right) \sigma_{E}}{\sigma_{\ln A}}
\end{aligned}
$$

The Standard Error about the fitted regression line was given as SE:

$$
\mathrm{SE}=\sqrt{\frac{\sum\left(\ln A_{i}\right)^{2}-\ln k_{i s o} \sum \ln A_{i}-\left(1 / R T_{i s o}\right) \sum E_{i} \ln A_{i}}{n^{-2}}}
$$

Standard Deviation of Slope $=\sigma_{1 / R T_{\text {iso }}}=\frac{S E}{\sqrt{\sum\left(E_{i}-\bar{E}\right)^{2}}}$

Standard Deviation of Intercept $=\sigma_{\ln T_{\text {iso }}}=S E\left(\frac{1}{n}+\frac{\overline{E^{2}}}{\sum\left(E_{i}-\bar{E}\right)^{2}}\right)^{1 / 2}$

\section{RESULTS AND DISCUSSION}

To examine the compensation effect, the pre-exponential factors $(A)$ were logarithmised and plotted against the activation energies $(E)$ that were obtained from the non-isothermal TGA experiments. These TGA data were tabulated in Table 1 . The values of the slope 
and intercept, as well as the resulting standard error and standard deviation of the slope and intercept were computed using the statistical formulas listed from Eq. 3 to 8. The resulting plot of $\mathrm{l} \mathrm{n} A$ vs. $E$, as shown in Fig. 1, was a linear curve. This linear relationship indicated the compensating effect between the kinetic parameters. A linear statistical analysis between $\ln A$ and $E$, of which also included a pair of kinetic data taken from Chornet and Roy's work on cellulose and $\alpha$-cellulose [7] suggested the following linear equation:

$\ln A=-1.5419(+4.212)+0.719(+0.1024) E$

The figures in the parenthesis represented the error limits at the $95 \%$ confidence level. The goodness of fit was reasonably rigorous; the correlation coefficient showed a value of 0.864 . The statistical analysis also showed that $\sigma_{1} / R T_{\text {iso }}<0.1 \mathrm{E}$, the significance of this rule, for which according to Galwey's research [8], established the compensation effect for the kinetic parameters derived from the pyrolysis of hardwood samples. Accordingly, the effect implied that for a series of related reactions, large apparent activation energy could co-exist over a narrow temperature range.

In terms of the study of wood pyrolysis as a solid-state kinetics, this compensating behaviour purported the simultaneous pyrolysis of a considerable number of components within wood $[9,10]$. It supported the view that within cellulose, two parallel competing reactions occurred for the primary degradation process [11,12], with the subsequent consecutive reactions occurring that accounted for the products first formed decomposing or reacting to form a new set of final products [13]. Side reactions may occur between the different sets of the final products [14].

On the note of compensation effect, it was however important to consider the controversy confounding the application of the compensating behaviour in cellulosic materials on its implication on the pyrolysis kinetics. Agrawal $[15,16]$ has objected the postulation of compensation effect occurring in cellulosic materials, in contradiction to the Chornet and Roy's work (1980, op., cit). The argument was grounded on the basis of theoretical analysis; no further experimental evidence has however been established. Wendlandt [17] has on the other hand suggested that compensation effect was indeed a mathematical effect thus limiting its implication on physical significance. The study of energetics thus offered a rigorous investigation into the processes of pyrolysis involving several components with the use of enthalpy of transition.

\section{Analysis of the Heat of Reaction $(\Delta H)$}

The typical DTG analysis (not shown) of hardwood pyrolysis normally showed a single DTG peak with a preceding shoulder, characterizing the pyrolysis reactions of hemicellulose and cellulose in the region $200-400^{\circ} \mathrm{C}$, and then ensued by a flat tailing section beyond $400^{\circ} \mathrm{C}$, which was associated with the pyrolysis of lignin [18-20].

It would be however presumptuous to fit a single reaction scheme across the shoulder and the main peak, even though it was commonly adopted in many research studies [21]. The analysis of the Arrhenius parameters derived from the nonisothermal TGA experiments in this study showed that the reactivity of the shoulder and the main DTG peak differed, suggesting that a separate designation of the conversion regime for a more rigorous evaluation of kinetic data (See Table 1). A number of kinetics works [22-24] have indeed 
adopted a similar approach of selecting conversion ranges instead of an entire conversion regime for the derivation of the order of reaction, or the kinetic parameters for the same reasons cited.

Table 1. First-order kinetic parameters for dynamic TGA of wood nitrogen atmosphere.

\begin{tabular}{|c|c|c|c|c|c|}
\hline \multirow[b]{2}{*}{ Material } & \multirow[b]{2}{*}{$\begin{array}{l}\text { Temperature } \\
\text { Range }\left({ }^{\circ} \mathrm{C}\right)\end{array}$} & \multicolumn{2}{|c|}{$\alpha$} & \multirow{2}{*}{$\begin{array}{c}\text { Activation } \\
\text { Energy } \\
\text { E } \\
(\mathrm{kJ} / \mathrm{mol})\end{array}$} & \multirow{2}{*}{$\begin{array}{c}\text { Frequency } \\
\text { Factor } \\
\text { A } \\
\left(\mathrm{min}^{-1}\right)\end{array}$} \\
\hline & & $W_{i}(\%)$ & $W_{f}(\%)$ & & \\
\hline \multirow[t]{3}{*}{$\begin{array}{l}\text { Balau } \\
\mathrm{B}(\mathrm{N}) \\
\end{array}$} & $210-310$ & 90.69 & 77.44 & 139.17 & 4.643E09 \\
\hline & $310-370$ & 77.44 & 29.09 & 199.40 & $2.062 \mathrm{E} 13$ \\
\hline & $370-550$ & 29.09 & 10.65 & 100.70 & $1.900 \mathrm{E} 03$ \\
\hline \multirow{3}{*}{$\begin{array}{c}\text { Durian } \\
\mathrm{D}(\mathrm{N})\end{array}$} & $230-320$ & 87.30 & 70.18 & 171.63 & 5.029E12 \\
\hline & $320-400$ & 70.18 & 18.54 & 212.04 & $1.509 \mathrm{E} 14$ \\
\hline & $400-550$ & 18.54 & 7.436 & 110.85 & 1.001E04 \\
\hline \multirow{3}{*}{$\begin{array}{l}\text { Kapur } \\
\text { K(N) }\end{array}$} & $210-300$ & 92.25 & 79.78 & 150.10 & 8.080E10 \\
\hline & $300-390$ & 79.78 & 34.65 & 169.65 & 9.912E10 \\
\hline & $390-550$ & 34.65 & 28.14 & 85.69 & 2.149E02 \\
\hline \multirow{3}{*}{$\begin{array}{l}\text { Meranti } \\
\mathrm{M}(\mathrm{N})\end{array}$} & $220-310$ & 87.24 & 74.86 & 148.03 & 3.534E10 \\
\hline & $310-400$ & 74.86 & 33.45 & 171.46 & 5.885E10 \\
\hline & $400-550$ & 33.45 & 26.22 & 93.13 & 7.002E02 \\
\hline
\end{tabular}




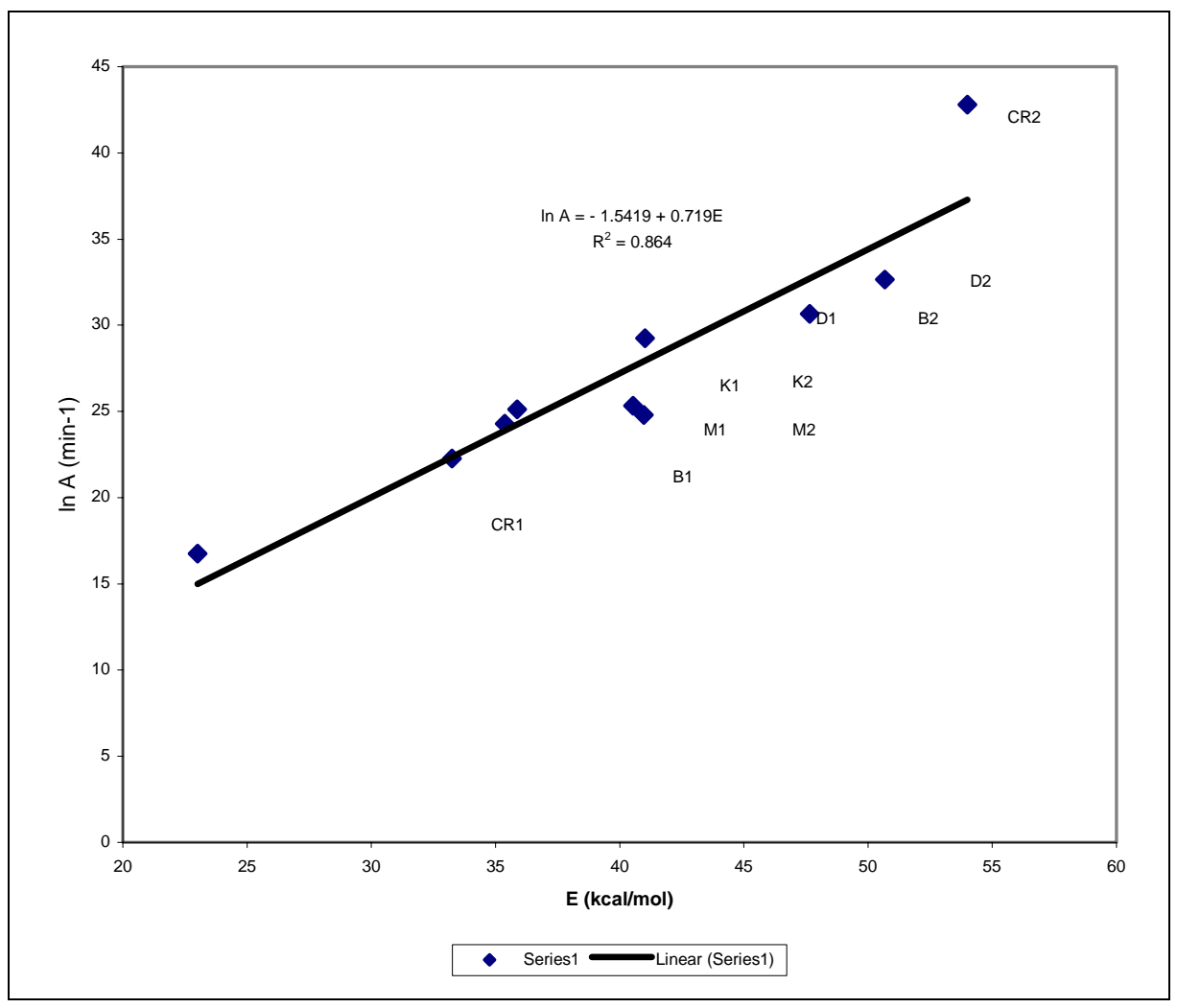

Fig. 1. Compensation effect of wood biomass.

Table 2. Legend of materials and the temperature regime.

\begin{tabular}{|l|c|c|}
\hline \multicolumn{1}{|c|}{ Material } & Symbols & $\begin{array}{c}\text { Temperature } \\
\text { range }{ }^{\circ} \mathbf{C}\end{array}$ \\
\hline Balau & B1 & $210-310$ \\
\hline & B2 & $310-370$ \\
\hline Durian & D1 & $230-320$ \\
\hline & D2 & $320-400$ \\
\hline Chornet \& Roy & CR1 & $280-325$ \\
\hline & CR2 & $325-350$ \\
\hline Kapur & K1 & $210-300$ \\
\hline & K2 & $300-390$ \\
\hline Meranti & M1 & $200-310$ \\
\hline & M2 & $310-400$ \\
\hline
\end{tabular}


Based on the kinetics parameter from TGA analysis, the pyrolysis processes was found to be first-order kinetics, where the TG data for the hardwood decomposition indicated a good fit for the three consecutive conversion phases. This experimental analysis was in good agreement with the mainstream assumption of the first order kinetics for bulk wood decomposition; it however did not quite agree with the proposed change of the reaction order with conversion phases [25-27], or adoption of second order kinetics [28]. The adoption of second order kinetics would be tenuous with the use of Coats and Redfern's method [29] on theoretical ground. Besides, the apparent activation energy in the shoulder regime appeared to associate closely with the value that characterized the dehydration pathway in cellulose pyrolysis. The activation energy in the shoulder regime were found close to $30 \mathrm{kcal} / \mathrm{mol}$ which was characteristic of the dehydration of cellulose. This observed low activation energy pyrolysis process would however also arise from the catalysis and autocatalysis effects, which promoted the secondary reactions. The decomposition of the primary pyrolysis products was now thermodynamically favoured, producing the characteristic low activation energy. The presence of the inorganic salts normally found in wood could also be responsible for this observed low activation energy in the pyrolysis associated with the shoulder regime [30,31].

The DSC analysis provided some insights as to the occurrence of the secondary reactions based on the heat of reaction $(\Delta H)$. The heat of pyrolysis measured for all the hardwood samples ranged between $-135 \mathrm{~J} / \mathrm{g}$ to $-304 \mathrm{~J} / \mathrm{g}$, the amount of which was too low to purport the secondary pyrolysis, which was a highly exothermic process that would produce another $-1200 \mathrm{~J} / \mathrm{g}$ to the heat evolution [32]. The heat of reaction showed that the secondary pyrolysis was absent in the shoulder regime even though the temperature of pyrolysis did not exceed $320^{\circ} \mathrm{C}$ which was necessary for the physical fissuring in wood to occur in order to promote the escape of the pyrolysis products. The absence of the secondary reactions and autocatalytic effects could be explained on the ground of the fine powder form of samples used in both DSC and DTA; the 40 mesh or $0.40 \mathrm{~mm}$ in diameter has been shown to be reaction-controlled for pyrolysis of cellulosic materials occurred in samples sizes less than $0.2 \mathrm{~cm}$ [33]. Only as the particle size increased would the relative influence of the transfer phenomena and secondary reactions therefore increase. The results therefore indicated that the secondary reactions were absent and the autocatalytic effects were minimized by the fine particle size of the samples used. The $\Delta H$ results were tabulated in Table 3 and the DSC analysis was shown in Figs. 2 to 5.

The absence of the secondary reactions as discussed therefore established a direct cause and effect relationship between the exothermic reactions and the primary pyrolysis of wood. The significance of the exothermicity associated with the primary pyrolysis process suggested that cellulose in this shoulder regime might pyrolyse by the dehydration and char-forming sequence, which were exothermic in contrast to the endothermic depolymersation sequence of cellulose [34]. 


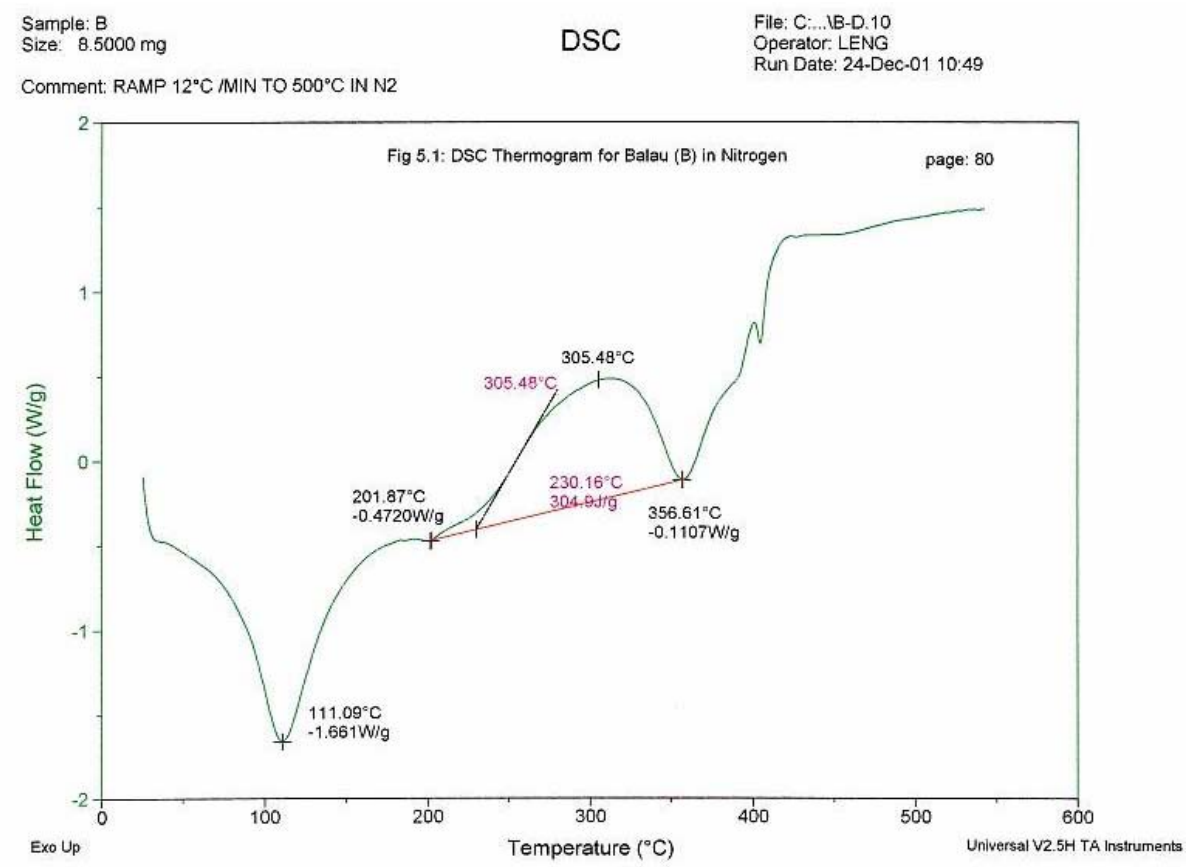

Fig. 2. DSC thermogram for Balau in nitrogen.

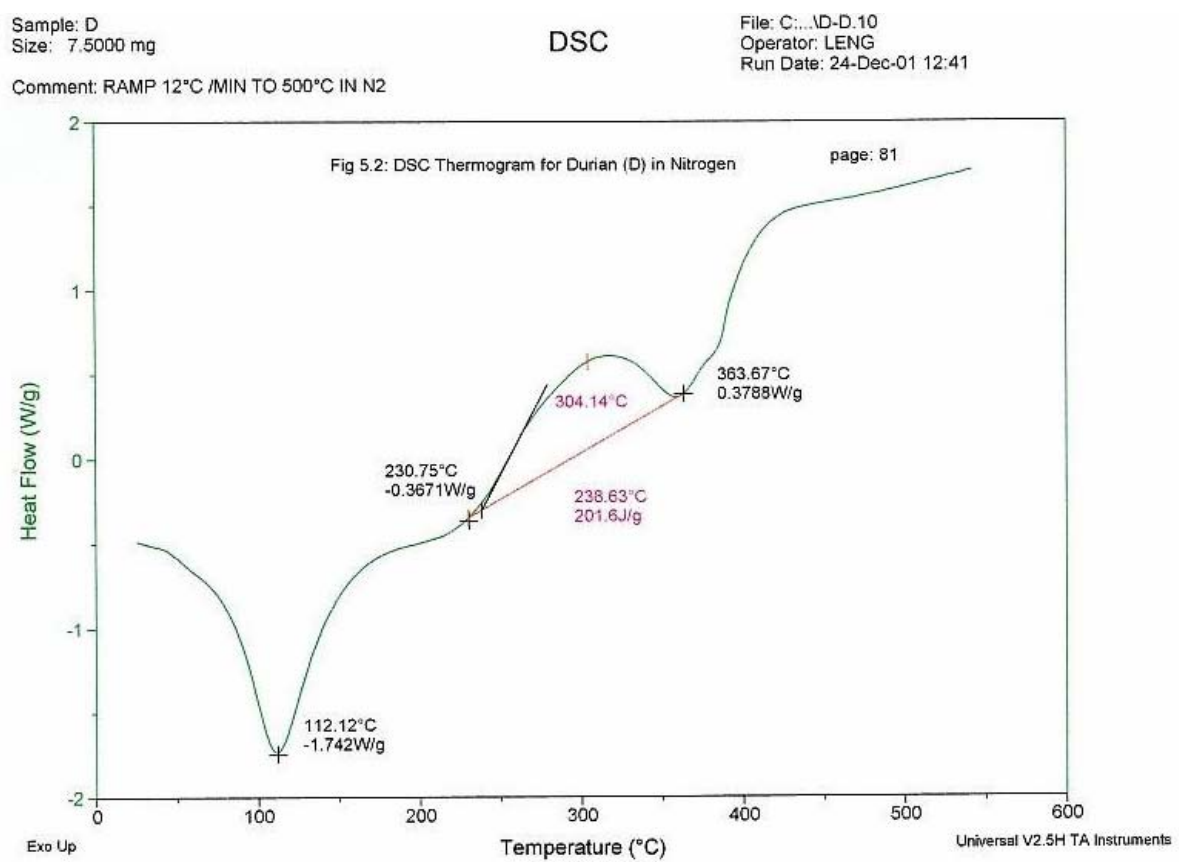

Fig. 3. DSC thermogram for Durian in nitrogen. 


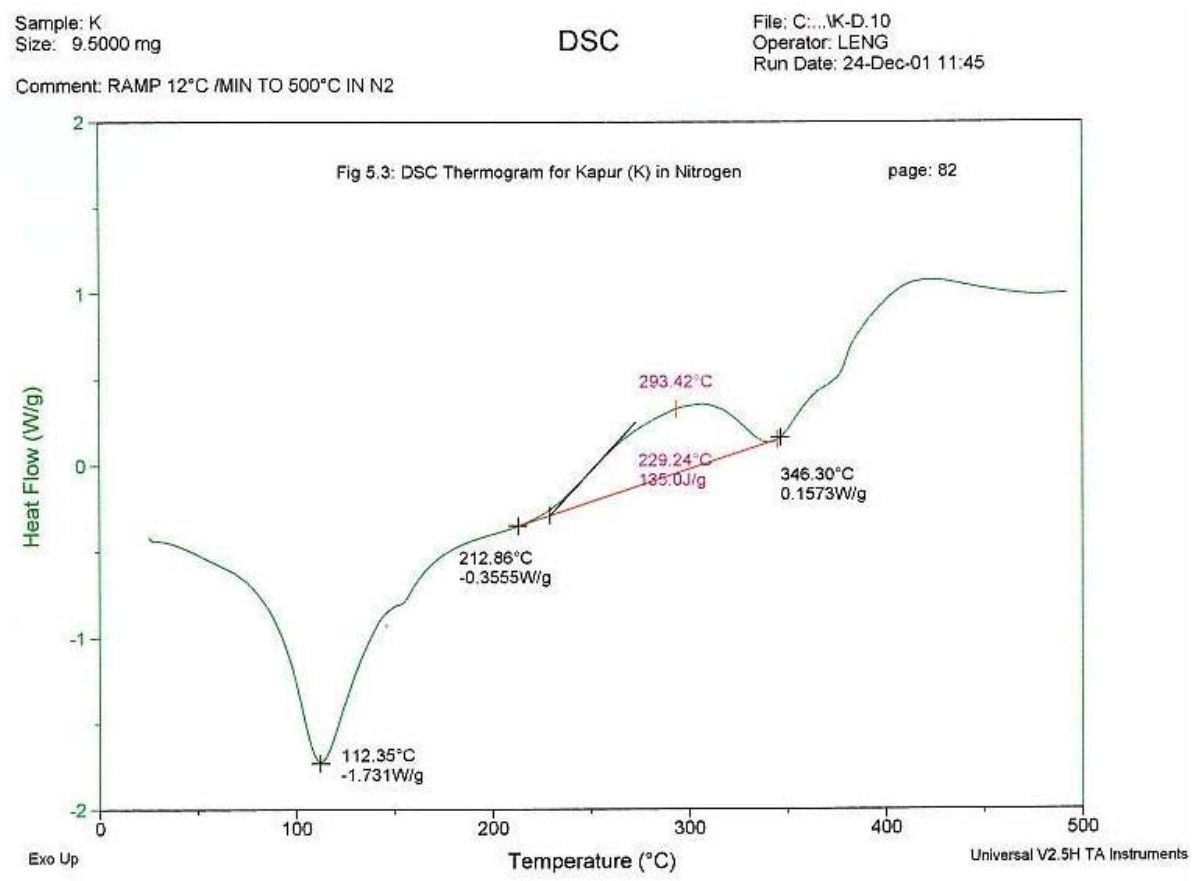

Fig.4. DSC thermogram for Kapur in nitrogen.

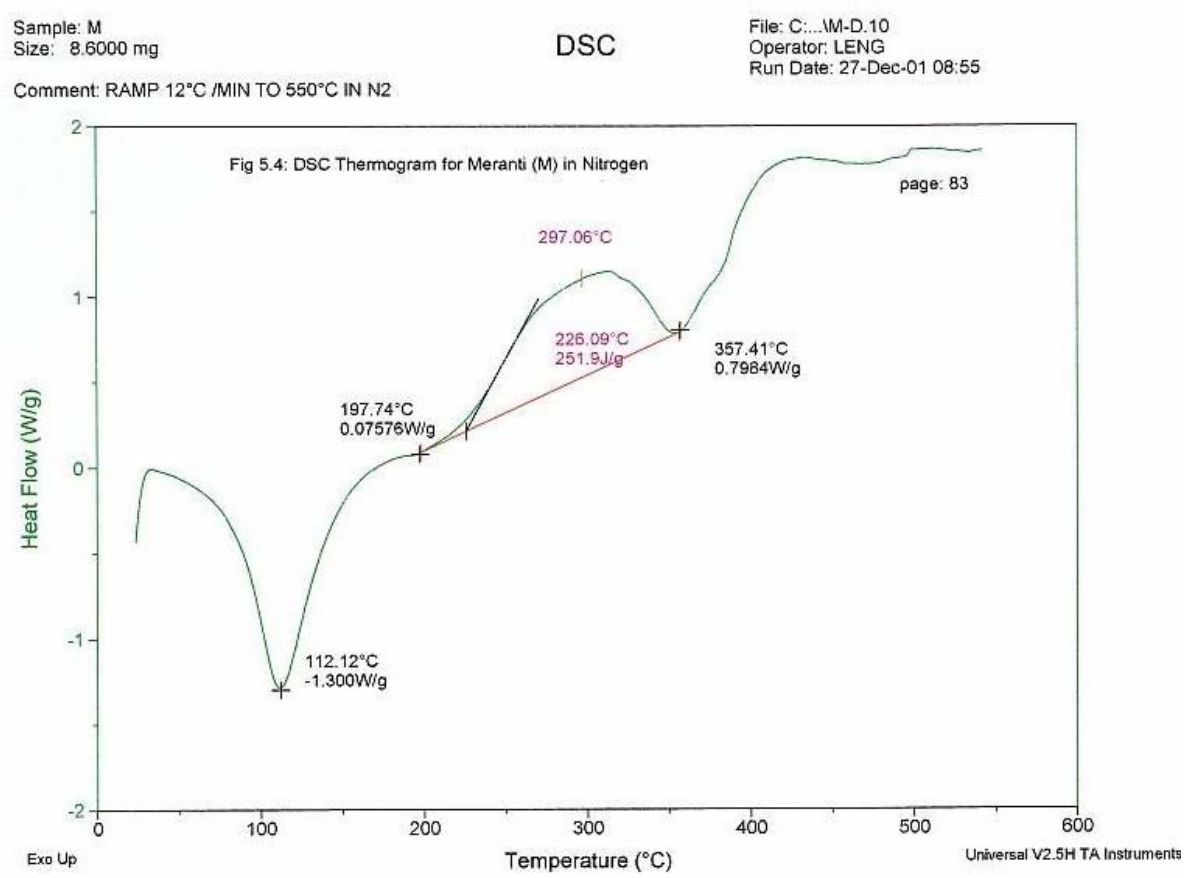

Fig.5. DSC thermogram for Meranti in nitrogen. 
Table 3. The DSC exothermic transition analysis of wood samples in nitrogen.

\begin{tabular}{|l|c|c|c|}
\hline Sample Code & $\begin{array}{c}\text { Temperature } \\
\text { Interval }\left({ }^{\circ} \mathbf{C}\right) \text { of } \\
\text { the Exothermic } \\
\text { Transition }\end{array}$ & $\begin{array}{c}\text { Peak } \\
\text { Temperature } \\
\left({ }^{\circ} \mathbf{C}\right) \text { of the } \\
\text { Exotherm } \\
\text { Transition }\end{array}$ & $\begin{array}{c}\text { Enthalpy of } \\
\text { Transition } \Delta \mathbf{H} \\
(\mathbf{J} / \mathbf{g})\end{array}$ \\
$\begin{array}{l}\text { T) Convention } \\
\text { for Exotherm }\end{array}$ \\
\hline Balau (B) & $201.87-356.61$ & 305.48 & -304.9 \\
\hline Kapurian (D) $(\mathrm{K})$ & $230.75-363.67$ & 304.14 & -201.6 \\
\hline Meranti (M) & $226.68-346.30$ & 293.42 & -135.1 \\
\hline
\end{tabular}

The data on energetics also suggested a switch in degradation pathway as temperature increased. In the next thermochemical regime of $300^{\circ} \mathrm{C}-400^{\circ} \mathrm{C}$, the activation energy leaped from the average value of $\mathrm{E}=35 \mathrm{kcal} / \mathrm{mol}$, to $\mathrm{E}=40 \mathrm{kcal} / \mathrm{mol}$ in $\mathrm{Kapur} \mathrm{K}(\mathrm{N})$ and Meranti $\mathrm{M}(\mathrm{N})$, and $50 \mathrm{kcal} / \mathrm{mol}$ in Balau $\mathrm{B}(\mathrm{N})$ and Durian $(\mathrm{N})$, indicating that the thermochemical conversion process had to overcome a bigger energy barrier in order to proceed in this conversion zone.

The derived apparent activation energy suggested a high-activation-energy conversion process, which differed from the previous low-activation-energy dehydration pathway. If the high-activation-energy conversion was purported to dominate, of which the highactivation-energy represented the depolymerisation as the alternative pathway [35], then the interpretation implied a switch between the two parallel competitive pathways, with transition from a low-activation-energy conversion to a high-activation-energy conversion with increasing temperature for the pyrolysis of cellulose in wood.

\section{CONCLUSIONS}

The statistical analysis of the Arrhenius parameters showed that compensating behaviour was present in the pyrolysis of hardwood sample, suggesting that the groups of rate reactions were responsible for the varied kinetic constants observed and collected from the TGA data. The energetics argument however provided a stronger argument for the domination of one particular rate process over the other, depending on the phase of the thermochemical conversion regime. On the ground of the energetic and heat of transition, the span of activation energies collated between $200-300^{\circ} \mathrm{C}$ and that of $300-400^{\circ} \mathrm{C}$ indeed suggested that as temperature increased, cellulose switched from dehydration to depolymerisation. These findings agreed with Tang's (1967) results but disagreed with Roberts' (1970) who has attributed the discrepancies to the minor variations that affect the conditions of pyrolysis such as catalytic or autocatalytic effects.

\section{REFERENCES}

[1] Agrawal, R.K., "Compensation Effect in the Pyrolysis of Cellulosic Materials," Thermochimica Acta, 90: 347-351 (1985).

[2] Lim, S.M., "The Study of High Temperature Decomposition of Wood and Its Kinetics in Response to Fire,” M.Sc. Thesis, National University of Singapore, Singapore, 2002, 143 p. 
[3] Roberts, A.F., "A Review of Kinetics Data for the Pyrolysis of Wood and Related Substances,” Combustion and Flame, 14: 261-272 (1971).

[4] Roberts, A.F., "The Heat of Reaction during the Pyrolysis of Wood," Combustion and Flame, 17: 79-86 (1971).

[5] Sim Sze Wai, Physical and Thermal Properties of Tropical Hardwoods and Their Wood-Polymer Composites, Undergraduate Dissertation, Department of Chemical Engineering, National University of Singapore, 1987.

[6] Agrawal, R.K., "Compensation Effect in the Pyrolysis of Cellulosic Materials," Thermochimica Acta, 90: 347-351, (1985).

[7] Chornet, E. and Roy, C., "Compensation Effect in the Thermal Decomposition of Cellulsoic Materials," Thermochimica Acta, 35: 389-393, (1980).

[8] Galwey, A.K., "Compensation Effect in Heterogenous Catalysis," Advances in Catalysis, 26: 247-322, (1977).

[9] Raveendran, K., Ganesh, A., and Khilar, K.C., "Pyrolysis Characteristics of Biomass and Biomass Components,” Fuel, 75 (8): 987-998, (1996).

[10] Antal, M.J., Jr., Advances in Solar Energy, Vol. 2, K.W. Boer and J.A. Duffle (eds.), American Solar Energy Society, New York, 1983, pp. 175-255.

[11] Arseneau, D.F., "Competitive Reactions in the Thermal Decomposition of Cellulose," Canadian Journal of Chemistry, 49: p. 632, (1971).

[12] Kilzer, F.J and Broido, A., "Speculations on the Nature of Cellulose Pyrolysis," Pyrodynamics, 2: 151-163, (1965).

[13] Agrawal, R.K., "Kinetics of Reactions Involved in Pyrolysis of Cellulose I. The Three Reaction Model," The Canadian Journal of Chemical Engineering, 66: 403-417, (1988).

[14] Shafizadeh, F., "Pyrolysis and Combustion of Cellulosic Materials," Advances in Carbohydrate Chemistr, 23: 419-414, (1968).

[15] Agrawal., R.K., "Compensation Effect in the Pyrolysis of Cellulosic Materials," Thermochimica Acta, 90: 347-351, (1985).

[16] Agrawal, R.K., "On the Compensation Effect," Journal of Thermal Analysis, 31: 69-82, (1986).

[17] Wendlandt, W.W., Thermal Analysis ( $3^{\text {rd }}$ Ed.), New York, Wiley, 1986, p. 80.

[18] Helsen, L., Van den Bulck, E., Mullens, S., and Mullens, J., "Low Temperature Pyrolysis of CCA-treated Wood: Thermogravimetric Analysis,” Journal of Analytical and Applied Pyrolysis, 52: 65-86, (1999).

[19] Antal, Jr., M.J., and Varhegyi, G., "Cellulose Pyrolysis Kinetics: The Current State of Knowledge," Industrial \& Engineering Chemistry Research, 34: 703-717, (1995).

[20] Grónli, M.G., A Theoretical and Experimental Study of the Degradation of Biomass, Doktor Ingeniǿrachandling NTNU (ITEV-rapport 1996:03), 1996, $115 \mathrm{p}$. 
[21] Lim, S.M., "The Study of High Temperature Decomposition of Wood and Its Kinetics In Response to Fire,” M.Sc. Thesis, National University of Singapore, Singapore, 2002, $104 \mathrm{p}$.

[22] Tang, W.K., "Effect of Inorganic Salts on Pyrolysis of Wood, Alpha-Cellulose and Lignin,” U.S. Forest Service Research Paper, FPL 71, 1967.

[23] Lee, T.V., "Kinetic Analysis and Modelling of Wood Pyrolysis under Nonisothermal Conditions," Ph.D. Thesis, Texas Technological University, 1982, 85 p.

[24] Tang, W.K. and Neill, W.K., "Effect of Flame Retardants on Pyrolysis and Decomposition of $\alpha$-cellulose,” Journal of Polymer Science, Part C., 6: 65-81, (1964).

[25] Tang, W.K., "Effect of Inorganic Salts on Pyrolysis of Wood, Alpha-Cellulose and Lignin," U.S. Forest Service Research Paper, FPL 71, 1967.

[26] Chatterjee, P.K. and Conrad, C.M, "Kinetics of the Pyrolysis of Cotton Cellulose,” Textile Research Journal, 36 (6):487-494, (1966).

[27] Lee, T.V., "Kinetic Analysis and Modelling of Wood Pyrolysis under Nonisothermal Conditions," Ph.D. Thesis, Texas Technological University, 1982, 110 p.

[28] Liu, N.A. and Wan, W.C., "Modelling the Thermal Decomposition of Wood and Leaves under a Nitrogen Atmosphere," Fire and Materials, 22: 103-108, (1998).

[29] Coats, A.W. and Redfern, J.P., “Thermogravimetric Analysis- A Review,” The Analyst, 88: 906-924, (1963).

[30] Raveendran, K., Ganesh, A., and Khilar, K.C., "Pyrolysis Characteristics of Biomass and Biomass Components,” Fuel, 75 (8): 987-998, (1996).

[31] Keattch, C.J. and Dollimore, D., "Chapter 9: Applications: B. Organic and Polymer Chemistry,” An Introduction to Thermogravimetry, ( $2^{\text {nd }} E d$.), London; New York: Heyden, 1975, p. 129-139.

[32] Roberts, A.F., "The Heat of Reaction during the Pyrolysis of Wood," Combustion and Flame, 17: 79-86 (1971).

[33] Maa, P.S. and Bailie, R.C., "Influence of Particle Sizes and Environmental Conditions on High Temperature Pyrolysis of Cellulosic Material," Combustion Science and Technology, 7: 257-269, (1973).

[34] Kilzer, F.J and Broido, A., "Speculations on the Nature of Cellulose Pyrolysis," Pyrodynamics, 2: 151-163, (1965).

[35] Kilzer, F.J and Broido A., "Speculations on the Nature of Cellulose Pyrolysis," Pyrodynamics, 2: 151-163, (1965). 